\title{
Razão e afeto nos Pia Desideriax inspiração para uma linguagem interconfessional contemporânea
}

\author{
Reason and affection in the Pia Desideria: inspiration for a
}

contemporary interconfessional language

\begin{abstract}
Razón y afecto en les Pia Desideria: inspiración para un lenguaje
interconfessional contemporáneo
\end{abstract}

HeLmut ReNDERS (iDa

\section{Resumo}

Interconfessionalidade e interculturalidade se (des)articulam por linguagens textuais, metafóricas e visuais compartilhadas, mediante de hibridizações, mestiçagens, resgates, aniquilações e inversões. O diálogo da inter-relacionalidade requer uma linguagem, no mínimo, parcialmente compatível, mutuamente acessível ou até comumente tecida. $\mathrm{O}$ artigo explora como exemplo, nessa perspectiva, primeiro, o significado original da metáfora pia desideria e seus apelos tanto racionais como afetivos e, segundo, usos confessionais em três obras do mesmo título, do católico Herman Hugo (1624) de Bruxelas, do pietista luterano Philipp Jacob Spener (1676) de Frankfurt, e do puritano Cotton Mather (1722) da Filadelfia. A partir dessa análise defende-se que, por um lado, certas interpretações e aplicações compartilhadas pelos autores representam um tipo indireto de interconfessionalidade e, segundo, que a metáfora dos pia desideria, justamente pelo seu significado original mais abrangente, e pelo seu amplo uso confessional pode servir como exemplo de uma linguagem religiosa capaz de sustentar e promover debates interconfessionais. Em relação às respectivas contribuições parciais, pode iluminar a discussão contemporânea, inclusive, sobre os papeis importantes tanto da razão como do afeto na vida geral e na vida religiosa hoje e a necessidade de uma linguagem religiosa capaz de articulá-la.

\footnotetext{
a Universidade Metodista de São Paulo, São Bernardo do Campo, SP, Brasil. Doutor em Ciências da Religião, e-mail: helmut.renders@metodista.br
} 
Palavras-chave: Interconfessionalidade. Linguagens religiosas. Pia desideria. Herman Hugo. Philipp Jacob Spener. Cotton Mather.

\section{Abstract}

Interconfessionality and interculturality are (dis)articulated through shared textual, metaphorical and visual languages, over hybridization, miscegenation, rescue, annihilation and inversion. The dialogue of inter-relationality requires a language, at least, partially compatible, mutually accessible or even commonly woven. The article explores as an example, in this perspective, first, the original meaning of the metaphor pia desideria and its appeals, both rational and affectional, and second, its confessional use in three works of the same title, by the Catholic Herman Hugo (1624) from Brussels, Lutheran pietist Philipp Jacob Spener (1675) from Frankfurt and Puritan Cotton Mather (1722) from Philadelphia From this analysis I argue that, on the one hand, certain interpretations and applications shared by the authors represent an indirect type of interconfessionality and, second, that the metaphor of the pia desideria may contribute, precisely because of its more comprehensive original meaning, and due to its wide confessional use, as an example of a religious language capable of sustaining and promoting inter-denominational debates. In relation to their respective partial contributions, it can illuminate the contemporary discussion, including the important roles of both reason and affection in general in life and religious life, pushing for a religious language capable of articulating them.

Keywords: Interconfessionalty. Religious languages. Pia desideria. Herman Hugo. Philipp Jacob Spener. Cotton Mather.

\section{Resumen}

La interconfesionalidad y la interculturalidad se (des)articulan a través de lenguajes textuales, metafóricos y visuales compartidos, mediante de hibridaciones, mestizaje, rescates, aniquilaciones $e$ inversiones. El dialogo de la interrelación requiere un lenguaje, al menos, parcialmente compatible, mutuamente accesible o comúnmente tejido. El artículo explora como ejemplo, en esta perspectiva, primero, el significado original de la metáfora pia desideria y sus apelaciones, tanto racionales como afectivas, y segundo, los usos confesionales en tres obras del mismo título, del católico Herman Hugo (1624) de Bruselas, El pietista luterano Philipp Jacob Spener (1675) de Franckurt y Puritan Cotton Mather (1722) de Filadelfia. A partir dessa análisis se argumenta que, por un lado, ciertas interpretaciones $y$ aplicaciones compartidas por los autores representan un tipo indirecto de interconfesionalidad y, por otro, como la metáfora de Pia desideria, precisamente por su significado original más comprensivo, y debido a su amplio uso confesional, puede servir como ejemplo de un lenguaje religioso capaz de sostener y promover debates interconfesionales. en relación a sus respectivas aportaciones parciales, puede iluminar la discusión contemporánea, incluyendo los importantes roles tanto de la razón como del afecto en la vida general y religiosa de hoy y la necesidad de un lenguaje religioso capaz de articularlo.

Palabras clave: Interconfessionalidad. Lenguas religiosas. Pia Desideria. Herman Hugo. Philipp Jacob Spener. Cotton Mather. 


\section{Introdução}

O título do dossiê "Cristianismo contemporâneo: desafios interconfessionais e interculturais" aponta duas frentes, uma interna, outra externa; ou seja, se refere tanto às relações entre confissões e denominações como das mesmas com o seu habitat cultural. Eu vou me aproximar ao tema dos desafios, a partir da proposta, primeiro: de uma linguagem capaz do diálogo por ser uma linguagem compatível, ou seja, por ter o potencial de ser aceita por todas as partes; segundo, por ser uma linguagem que atende certas demandas culturais contemporâneas. Quais são estas demandas? Entre as muitas, detecto uma aparente contradição: por um lado, propõe-se desconstruir uma lógica cartesiana, departamentalista, hierárquica e excludente; por outro lado, se questiona a tendência do substituir objetividade pela subjetividade, facticidade por opiniões, apelos argumentativos por apelos emocionas. De certo modo, se secularizou um debate que se apresentou por séculos como uma disputa entre um protestantismo supostamente apelando mais à razão humana e a um catolicismo supostamente mais se dirigindo ao aspecto emotivo do ser humano. Em seguida, demonstro primeiro como se dá essa negociação entre o racional e emocional. Para isso investigo o uso da mesma metáfora, pia desideria, por três autores: um católico, um luterano e um reformado. Depois pergunto se essas releituras interconfessionais não possam servir como inspiração para uma linguagem religiosa contemporânea interconfessional que articula um dos desafios da cultura contemporânea.

Dependendo da tradição religiosa, evoca o título Pia desideria associações distintas. Católicos e especialistas em livros com emblemas vão se lembrar da Pia desideria (1624) de Herman Hugo (1588-1629), um jesuíta que viveu nos Países Baixos. Luteranos, especialmente, especialistas da história do pietismo, iriam de imediato falar da obra de Philipp Jacob Spener (1635-1705), publicada em 1675, considerada o texto fundante do pietismo, no mínimo, em termos programáticos. E, finalmente, partiriam teólogos reformados - talvez - de uma versão dos pia desideria de 1722, escrita por Cotton Mather (1663-1728), por sua vez uma figura emblemática puritana estadunidense. Seja o que for, fica evidente que essas três obras representam uma apreciação interconfessional a partir da mesma metáfora. De fato, a história das edições dessas obras sugere que as 
primeiras duas influenciaram durante séculos ambientes religiosos, enquanto a obra puritana estadunidense exerceu um significado mais local ${ }^{2}$, apesar de que o autor da última, Cotton Mather, se equivale em importância para seu contexto dos EUA ${ }^{3}$ à importância de Philipp Jacob Spener para o luteranismo e Herman Hugo para o catolicismo, sendo ele hoje considerado o pai do avivalismo estadunidense. A diferença entre os três é que Spener e Hugo se tornaram internacionalmente conhecidos, justamente, pelos seus Pia desideria, ${ }^{4}$ Cotton Mather, porém, não.

Quando se procura uma tradução de Pia desideria ao português, lembra Gilda Maria Whitaker Verri (2006, p. 68) que a primeira edição de Hugo em língua portuguesa traduzia "desejos piedosos", o que depois se manteve. Quanto à obra de Spener, pôde-se manter o latim (SPENER, [s.a.]), a tradução "desejos piedosos" (cf. por exemplo, BRANDT, [s.a.]) — ou "piedosos desejos" (COLLINS, 2000, p. 160) — ou se fazer um adendo: "desejos

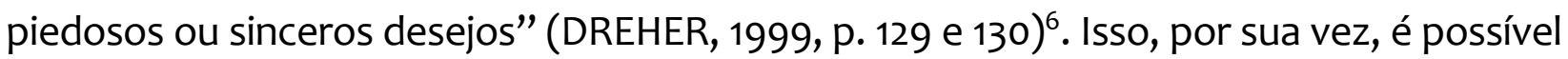
pela amplitude do significado da metáfora original. Pia Desideria é composto por um adjetivo - pius, aqui no gênero neutro pium - e um substantivo - desiderium -, ambos no nominativo plural. Pius, pious no inglês e piedoso em português, mas, fromm em alemão, pode apontar a participação em práticas religiosas consideradas "boas" — como tradução quase literal de eusebeia com seu prefixo "eu" ou "bom" - , ou uma utilidade ou valência mais genérica, segundo o uso da palavra "fromm" ainda por Lutero". Equivalente ao inglês que pode traduzir desideria por wishes, desires ou longings, ou ao alemão em que pode se referir a Wünsche, Bitten, Anliegen, Sehnsüchte, Vergnügen, ou Verlangen, no português podemos falar de quereres, pedidos, aspirações, saudades, prazeres, e desejos. Portanto, o

\footnotetext{
${ }^{2}$ Segundo o Wordcat, as três obras têm histórias de edição em diferentes línguas com pesos bem diferentes: constam da obra de Hugo cento e noventa edições, a última vez de 2018; da obra de Spener cento e dezesseis edições, a última de 2005, e da obra de Mather duas edições, a última 2005.

3 Virginia Bernhardt (1980, p. 388) comenta que "É irônico que Cotton Mather, que deixou o diário mais extenso de todos os puritanos americanos e a maior bibliografia do que qualquer outro autor americano, ainda continua sendo um enigma dois séculos depois da sua morte".

${ }^{4}$ Apesar disso, é Mather também mundialmente conhecido, entretanto, não pela sua versão de uma Pia desideria, mas, por causa da sua participação decisiva nos julgamentos e nas condenações das chamadas "bruxas" de Salem.

${ }^{5}$ Também documento que uma edição foi enviada para Pernambuco em 1795.

${ }^{6}$ Glauco Barreira Magalhães Filho (2014, p. 4) traduz "Desejos de piedade". Esta tradução enfrenta dois obstáculos: primeiro, pius é um adjetivo - o substantivo equivalente a piedade seria pietas -; segundo, pia é um plural, não um singular.

7 Um conhecimento que Philipp Jacob Spener, um especialista de Lutero, certamente ainda tinha.

Rev. Pistis Prax., Teol. Pastor., Curitiba, v. 12, n. 3, p. 754-773, set./dez. 2020
} 
que o latim deixa em aberto ou eventualmente, relaciona até de uma forma indissolúvel, entretanto, dinâmica, as traduções colocam em departamentos distintos, se não, opostos, basicamente, ou no campo das racionalidades e das decisões ou no campo dos afetos, eventualmente, até das emoções e dos sentimentos. Atrás dessas variações de tradução transparecem, então, diferentes mundos de compreensão e da construção religiosa, como também das práticas religiosas. Vistas em conjunto, entretanto, eles revelam ao mesmo tempo um potencial para estabelecer uma linguagem religiosa que explora aspetos racionais e afetivos em conjunto. Investigo, em seguida, as opções pela linguagem tomadas historicamente, para depois explorar a amplitude da metáfora pia desideria como inspiração para uma linguagem religiosa contemporânea que atende uma demanda atual da cultura enriquecida por contribuições confessionais distintos.

\section{Os pia desideria de Hugo, Spener e Mather: acentos racionais e afetivos de linguagens religiosas na modernidade}

\section{A Pia desideria de Herman Hugo}

A obra de Herman Hugo (1624) é um livro com emblemas, escrito em latim organizado em três capítulos centrais, antecipados por uma dedicatória e introdução, seguidos por índices dos versículos bíblicos de cada capítulo:

Bediano Morange Doctori [dedicatória];

Desejo [de estar n]as colinas eternas de Jesus Cristo [Introdução];

Primeiro livro: lamentos de uma vida penitente, p. 1-58;

Segundo livro: desejos [votos, orações] de uma vida santa, p. 59-120;

Terceiro livro: suspiros de uma vida amada, p. 121-181;

Lista do primeiro livro: lamentos de uma vida penitente, p. 182-185;

Lista do segundo livro: desejos [votos, orações] de uma vida santa, p. 186-188;

Lista do terceiro livro: suspiros de uma vida amada, p. 189-191.

Cada um dos três capítulos principais contém 15 seções e cada uma delas é dividida em três partes: (a) uma gravura com um versículo bíblico abaixo dela, (b) uma meditação e (c) uma citação breve ou de um pai da igreja ou de um teólogo escolástico.

${ }^{8}$ Até 1759 , ano da proibição dos jesuítas, existiam 42 edições latinas e, além disso, tradições em quase todas as línguas europeias.

Rev. Pistis Prax., Teol. Pastor., Curitiba, v. 12, n. 3, p. xxx-xxx, set./dez. 2020 
Isso corresponde à composição por três elementos de um livro com emblemas: (a) a pictura - ou a imagem (fig. 2) -, (b) a inscriptio - ou o título - e (c) a subscriptio ou o texto explicativo [prosa ou poesia]. Veja em seguida (Figuras 1 e 2):

Figura 1

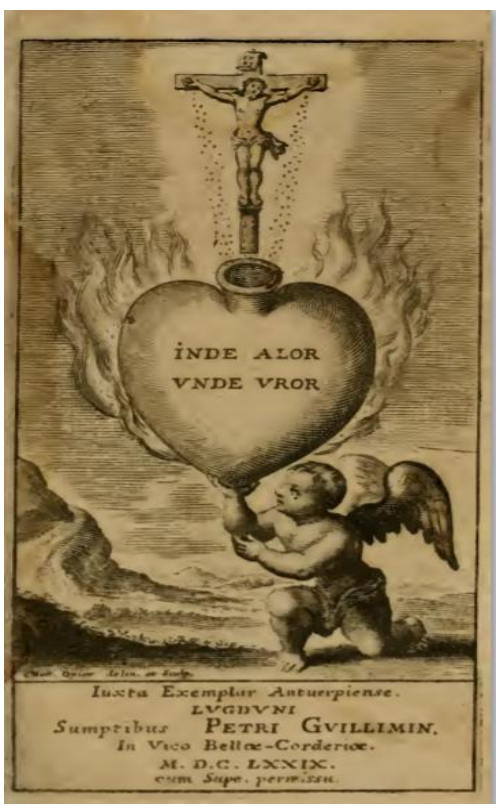

Fonte: HUGO, Herman. Pia Desideria. 1629.
Figura 2

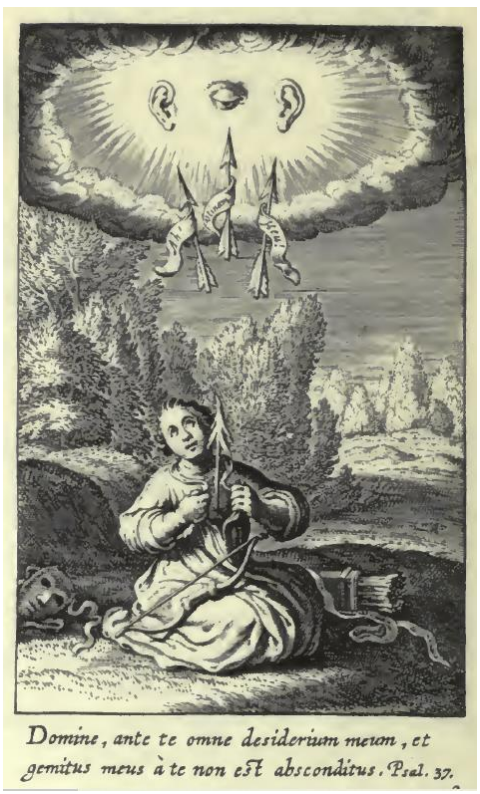

Fonte: HUGO, Herman. Pia desideria, 1624.

Nos espaços ociosos entre as 45 seções encontram-se ainda como tailpieces os elementos gráficos para finalizar uma seção, ornamentos gráficos como florais, formas abstratas ou máscaras ${ }^{9}$ (p. 15, 19, 26, 31, 79, 83,188) e três referências religiosas imagéticas específicas: (a) seis vezes, o "Véu de Verônica" (Figura 3), inclusive, como primeira e a última ornamentação; três vezes, o "coração com chamas" (Figura 4), uma alegação à theologia cordis jesuíta, e mais três vezes a sigla IHS (Figura 5) como referência à Sociedade de Jesus, que, inclusive, também aparece no título. Todos esses elementos visuais sinalizam em conjunto, primeiro, que os três capítulos principais promovem uma espiritualidade de três trajetos, composta (a) pela via purgativa ou da

\footnotetext{
${ }^{9}$ Não excluo plenamente a possiblidade que essa "máscara" represente Sileno, um demônio greco-romano, companheiro de Dionísio, que aparece, por exemplo, em representações do inferno. Esta iconografia foi muito usada desde a época medieval alta e durante toda a renascença para representar o ameaça pelo diabólico.

Rev. Pistis Prax., Teol. Pastor., Curitiba, v. 12, n. 3, p. 754-773, set./dez. 2020
} 
purificação, (b) pela via iluminativa ou da iluminação e (c) pela via unitiva ou da perfeição, entendidos como a procura de uma profunda experiência no interior da pessoa ou no coração como unidade ou intimidade com a divindade.

Figura 3 - HUGO, Herman. Pia desideria, 1629. p. 3, 47, 63, 103, 141,182 [Detalhe: "Véu da Verônica"]

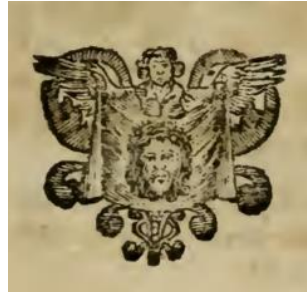

Fonte: archive.org
Figura 4 - HUGO, Herman. Pia desideria, 1629. p. 23, 51, 137

[Detalhe: "coração com chamas"]

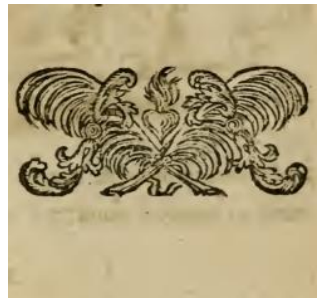

Fonte: archive.org
Figura 5 - HUGO, Herman. Pia desideria. p. 27, 125, 185;

[Detalhe: logo dos jesuítas]

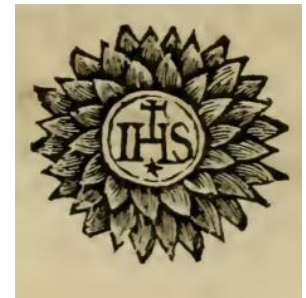

Fonte: archive.org

Segundo, nas 45 pictura (por exemplo Figura 2), sempre aparecem duas pessoas, uma delas com asas e auréola. Ela, como também o próprio coração com chamas (Figuras 1, 4) representam o amor divinus, o amor de Deus ${ }^{10}$. A outra figura representa a anima ou a vida humana que é conduzida pelo amor divinus em seu caminho em busca do céu ou "das colinas de Jesus Cristo". O "Véu da Verônica" representa tanto uma mística que envolve imagens como ele também é considerado uma das relíquias mais apreciadas, ou seja, reafirma-se a mística das relíquias em alta como proposta das três vias na mística medieval. Uma boa parte dos livros com emblemas da religio cordis da reforma católica é organizado da mesma forma e com o propósito parecido de ensinar o caminho para a união de Deus, apesar das diferenças pontuais entre eles (cf. RENDERS, 2017, p. 239-363). Em geral, seguem uma ênfase encontrada nos exercícios de Ignácio de Loyola (PAIS, 2007, p. 188) e sistematizado pelo seu seguidor na liderança da Sociedade de Jesus, Jerônimo Nadal (1507-1580). Nadal não foca no papel da razão nem no equilíbrio entre razão e coração na religião, mas no impacto emocional ou em uma dinâmica religiosa que parte da comoção, causada por experiências místicas, para depois avançar para a ação. Ele chamou isso Espiritu, corde et practice ou “do Espírito, para o coração, à prática”. "[...] Para

${ }^{10}$ Esta iconografia foi criada por Otto van Veen (WARNKE, 2005, p. 122), primeiro, com um cúpido em uma versão secular (VAENIUS, 1608), depois com o amor divinus em uma versão religiosa (cf. BUSCHHOFF, 2004).

Rev. Pistis Prax., Teol. Pastor., Curitiba, v. 12, n. 3, p. xxx-xxx, set./dez. 2020 
Jerônimo, a contemplação das verdades divinas deveria partir da emoção e o coração e não a mente seria a chave da elevação espiritual. Pelo Espírito Santo, a Palavra torna-se clara. No amor e na afeição do coração o Espírito Santo se manifesta" (BANGERT apud AULER, 2007). Concluímos que os Pia Desideria de Hugo apelam a paixões religiosas humanas que expressam temor e afeto em relação a Deus.

\section{A Pia desideria de Philipp Jacob Spener}

A obra Pia desideria de Philipp Jacob Spener surgiu como uma apresentação de uma publicação de sermões de Johann Arndt (1555-1621) ${ }^{11}$. Logo depois, em 1675 foi lançado como livro autônomo. Também esta obra é dividida em duas partes semelhantes que seguem uma apresentação ou dedicatória:

1. Aos líderes e pastores de todas as igrejas cristo-evangélicas, p. 2-912

2. Graça, luz e salvação de DEUS do Pai celestial por meio de Jesus Cristo no Espírito Santo, a todos[as] que procuram o SENHOR, p. 9-4713;

3. Agora, já somos interessados na religião certa e verdadeira / também pensamos em maneiras e meios para mantê-la, p. 47

3.1 Que se pense / em trazer a palavra de Deus mais abundantemente entre nós, p. 53-54;

3.2"[...] que também de outro jeito as pessoas seriam introduzidas nas escrituras, p. $54^{14}$;

3.3 Também não deve [...] ser inútil / quando novamente se colocaria em movimento o velho modo apostólico das reuniões da igreja, $\mathrm{p}$. 55;

3.4 Que a integridade do ensino [...] seja preservada [...] por meio do arrependimento e uma vida santa, p. 64;

3.5 Mas como o pregador [...] precisa assumir a maior parte $[\ldots], \mathrm{p}$. 67 ;

$3.6[\ldots]$ in den Controversiis selbs maß gehalten $[\ldots]^{15}$, p. 74 .

O subtítulo alemão indica a intenção principal da obra: "Pia desideria: oder das herzliche Verlangen nach gottgefälliger Besserung der wahren evangelischen Kirchen".

\footnotetext{
11 O formato de uma "apresentação".

12 Seguimos a paginação da edição crítica de Aland (SPENER, 1955).

13 Spener não usa um título ou subtítulo para marcar essa mudança. Mas, o tom e a direção texto mudam radicalmente, de análise e denúncia para esperança e desafia da fé.

${ }^{14} \mathrm{O}$ assunto começa na linha 20, mas, a frase decisiva encontra-se na linha 28.

15 "[...] até nas controvérsias procurar a medida certa [...]".

Rev. Pistis Prax., Teol. Pastor., Curitiba, v. 12, n. 3, p. 754-773, set./dez. 2020
} 
Herzlich significa cordial, Verlangen oscila entre demanda, exigência, querer, desejo e ter saudade de, ou seja, requer interpretação ${ }^{16}$. Em meio a sua linguagem barroca, cheia de figuras de linguagens pomposas, rege a racionalidade que foca no argumento e não na comoção. Veja as palavras de destaque na primeira página (Figura 7), nas linhas $4 \mathrm{e}$ 11/12 e 20: "VORSTEHERN UND HIRTEN"17, "[...] wünsche von dem Vater des Lichts und Geber alles Guten ERLEUCHTETE AUGEN DES VERSTÄNDNIS / zu erkennen"18 e - em letra já um pouco menor, mais, ainda assim maior do que o restante - "FLEISS UND EIFFER I WACKER ZU SEYN"19. "Compreensão", "dedicação", "esforço" e "conhecer" são palavras que apelam à razão e não à comoção.

Figura 6 - Primeira página do tratado

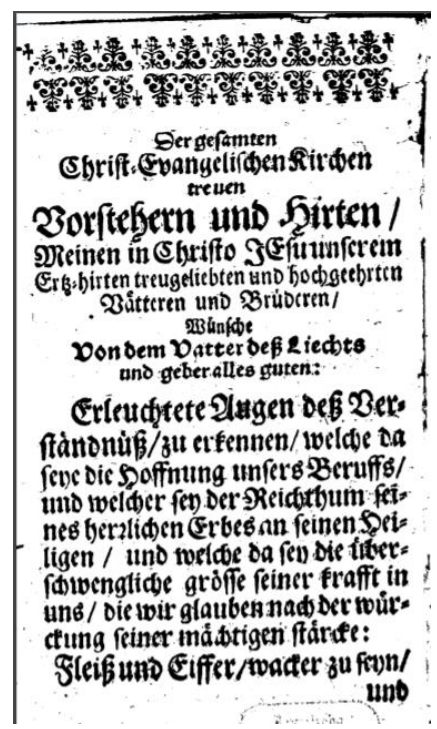

Fonte: SPENER, Philipp Jacob. Pia desideria, 1676. p. 1
Figura 7 - Primeira página da obra

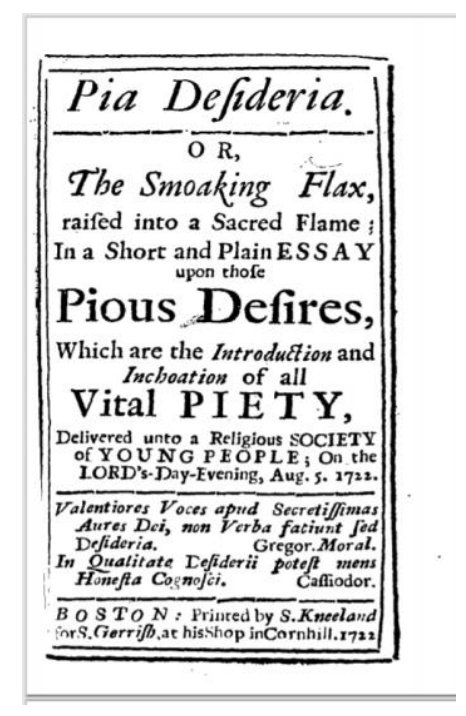

Fonte: MATHER, Collin. Pia desideria, 1722

A escolha de interlocutores fortalece essa impressão. Spener cita teólogos da ortodoxia luterana e pais da igreja, e quando ele os cita, ele faz isso em latim, inclusive por trechos longos (e sem traduzi-los). ${ }^{20}$ Os pia desideria de Spener apresentam um

\footnotetext{
16 "Pia desideria: ou o querer cordial do aperfeiçoamento das verdadeiras igrejas evangélicas que agrada a Deus".

17 "LÍDERES [literalmente: Aqueles que estão na frente, o autor] E PASTORES [...]".

18 "deseja do pai da luz e de todo que o bom OLHOS ILUMINADOS DA COMPREENSÃO / [para conhecer]". 19 "DEDICAÇÃO E ESFORÇO / [PARA] ENXERGAR COM CORAGEM".

${ }^{20}$ Além disso, criou uma tradução do texto inteiro para o latim já em 1678 (cf. SPENER, 1955, p. iii).

Rev. Pistis Prax., Teol. Pastor., Curitiba, v. 12, n. 3, p. xxx-xxx, set./dez. 2020
} 
programa de reforma, em primeiro lugar, da igreja e, indiretamente, da sociedade, em seis pontos: (a) A Bíblia deve ser estudada de forma mais profunda; (b) os collegia pietatis da igreja primitiva devem ser reintroduzidos; (c) o sacerdócio universal deve ser fortalecido; (d) as polêmicas interconfessionais devem ser encerradas; (e) o estudo da teologia deve ser reformado; ( $f$ ) a pregação deve focar na missão e no trabalho pastoral. Spener não conduz ao recuo do mundo, mas ao seu enfrentamento e à leitura comunitária e leiga da Bíblia. Além de desafiar o clero e a ortodoxia luterana, é essencialmente anti-entusiasta. Sattler (1988, p. 324) tem por isso razão quando ele afirma que

A Pia Desideria é uma manifestação do pietismo no seu melhor, pois é brutalmente honesta, irênica e profundamente preocupada com o bem-estar da igreja. Reflete o princípio pietista básico de que indivíduos renovados transformarão a igreja e a sociedade, e o verdadeiro cristianismo se reflete em indivíduos caídos, mas fiéis, vivendo pela glória de Deus e pelo bem do próximo.

Concordo com Sattler que Spener se preocupa com o indivíduo, mas creio que ele ainda mais foca na importância da reforma da igreja como meio para servir cada indivíduo melhor, criando novos espaços onde leigos e leigas possam assumir novos papeis dentro da proposta do sacerdócio universal, e que a linguagem aplicada para esse propósito é argumentativa.

\section{A Pia desideria de Cotton Mather}

O título completo da obra de Cotton Mather, escrita em 1722, Pia Desideria: or, the smoaking flax, raised into a sacred flame: in a short and plain essay upon those pious desires, which are the introduction and inchoation of all vital piety, delivered unto a religious society of young people ${ }^{21}$ anuncia o texto como uma orientação espiritual, o que o aproxima desde o início mais à obra de Hugo do que de Spener. Trata-se de uma fala ou conferência que se tornou texto. A primeira impressão é de um texto "simples",

\footnotetext{
${ }^{21}$ Pia Desideria: ou, o um pavio fumegante, transformado em uma chama sagrada, em um ensaio curto e claro sobre esses desejos piedosos, que são a introdução e a iniciação de toda piedade vital, entregue a uma sociedade religiosa de jovens.

Rev. Pistis Prax., Teol. Pastor., Curitiba, v. 12, n. 3, p. 754-773, set./dez. 2020
} 
em prosa, sem poesias, que não contém nenhum elemento visual, inclusive nenhum elemento de ornamentação (Figura 7). $\mathrm{O}$ autor organiza o texto em três níveis:

1. They servant who desires to fear my name, p. 1-8;

1.1 The first thing [...] the things which are to desire, p. 4-5;

1.2 Secondly [...] the fear of God is the very same the love of God, p. 57;

1.3 Thirdly [...] the love of God brings on the life of God, p. 7-8;

2. In the second place, the comfort of these pious desires, p. 8-21;

2.1 First, all the good of the new creature, begins in good desires, p. 810 ;

2.2 Secondly, desires places aright and flaming aright, p. 10-13;

2.2.1 [I] What a conviction are the strangers to piety, p. 13-15;

2.2.2 [II] What an encouragement may be given to those, who have some symptoms of piety, p. 13-15;

2.2.3 [III] But some care must be taken that none of us ly under any soul undoing delusion, p. 15-21;

2.2.4 [IV] To have done me think one word for the animation of early piety, p. 21-22.

Os dois elementos do tema dos pia desideria, pius/pium e desiderium, o texto explora e articula as duas nas duas partes com pesos diferentes: na primeira parte ele discute o que o ser humano deve desejar, e na segunda ele distingue tipos de piedade, e como ela seja promovida. O título mesmo já anuncia esta dupla ênfase quando ele destaca ao lado das palavras PIA DESIDERIA e PIOUS DESIRES também VITAL PIETY. Em Mather, portanto, "piedade vital" não é uma segunda proposta de tradução de Pia Desideria como em Glauco Barreira Magalhães Filho (2014), mas antes um jogo habilidoso de palavras que estabelece uma ordem ou sequência: uma piedade vital, ou seja, uma piedade com vida que sustenta e alimenta a vida religiosa, é o resultado da forma certa de desejar. De fato, Mather usa 16 vezes o verbo desejar, 73 vezes o substantivo desejo e 2 vezes o adjetivo desejoso; 23 vezes o substantivo piedade, 30 vezes, piedoso. Pela ampla escolha da forma verbal e da forma como ela é usada, a ideia da escolha e do querer está presente, mas o aspecto do sentimento, da emoção, parece dominar ou orientar este querer. Em outras palavras, as escolhas são acompanhadas por fortes emoções, em especial, o temor de Deus e o amor para com Deus, inclusive, nesta sequência, já que pelo primeiro se apela a "desejar ter temor de 
Deus" e o que somente depois avança em algo que pode ser descrito como "amor para com Deus". Em toda primeira seção, entretanto, predomina o tema do medo sobre a sensação do amor. Quando se pergunta em relação às fontes e inspirações de Mather, devemos considerar os seguintes aspectos. Cotton Mather era puritano da terceira geração (MIDDLEKAUF, 1999) e se correspondia com pietistas alemães (LOVELACE, 1979), em especial, August Hermann Francke (1663-1727), o seguidor mais famoso de Philipp Jacob Spener. Segundo Mark A. Noll (2008, p. 405) “[...] era famoso por ser hiperativo, mas, também era um estudioso, consciencioso e piedoso de uma forma tocante"22.

\section{Relações diretas e indiretas entre os autores e os seus Pia Desideria}

Hugo faleceu antes da publicação das outras duas obras e Spener antes do lançamento do texto de Mather ${ }^{23}$ mas, Spener e Cotton conheciam a obra de Hugo ${ }^{24}$. Mather, inclusive, consultava a versão em latim já que uma expressão que ele usa "atiramos as flechas dos nossos desejos ao céu" (RICK, 2015, p. 89) 25 - parece transformar o conteúdo visual da gravura de abertura da versão latina da Pia desideria de

22 Um tema pouco tratado é sua atitude diante da escravidão e a sua atitude em relação aos povos indígenas dos EUA. Segundo Christopher Leslie Brown (2008, p. 521) demonstrou esforços a favor da sua "humanização", porém, não era abolicionista: "A cristianização da instituição da escravidão era o objetivo dos religiosos líderes tão diversos quanto o jesuíta Anthony Vieira no Brasil, o Quaker George". E W. R. Ward (2008, p. 331) comenta que "Cotton Mather e Jonathan Edwards concluíram ainda mais pejorativamente que os índios não eram judeus, mas cananeus, ou que haviam sido trazidos da Europa pelo próprio diabo para ser seu povo peculiar intocado por Influência cristã".

${ }^{23}$ Isso não significa que Spener não conhecia a literatura puritana. Pelo contrário. Peter Damrau (2006, p. 63-65) indica que Spener conheceu Robert Person, Lewis Bayly, Emanuel Sonthom. Em outro lugar menciona que especialmente durante a Guerra dos 30 anos, cerca de 50 obras puritanas tinham sidas traduzidas para o alemão e publicadas na Alemanha em 138 edições (DAUMRAU, 2006, p. 17). Na mesma direção argumenta também Chaoluan Kao (2018, p. 149-155). Assim se estabelece uma ideia de fontes compartilhados também entre Spener e Mather. A edição inglesa de Hugo data de 1686 (RASPA, 2000, p. 63), mas, Mather, um ex-aluno da escola de latim de Boston e estudante de Harvard, era fluente na escrita e leitura do latim.

${ }^{24}$ Segundo Volker Meid (2009, p.253), foram lançadas as primeiras três edições da pia desideria de Hugo em alemão nos anos 1661,1662 e 1675. Entretanto, Spener - como também Franke e Bengel - dominava o latim.

${ }^{25}$ Mather usa o motive também na sua obra Magnalia Christi Americana (MATHER, 1702, p. 54 e 117) quando chama uma oração intensa e espontânea "ejuculatory prayer" e a compare a uma flecha atirada aos céus, algo que segundo Lovelace (1979, p. 125), já seu pai fazia, com quem ele dividia por um longo tempo, o trabalho na Igreja em Boston.

Rev. Pistis Prax., Teol. Pastor., Curitiba, v. 12, n. 3, p. 754-773, set./dez. 2020 
Herman Hugo em texto, uma gravura que na versão inglesa não foi mantida. ${ }^{26} \mathrm{O}$ emblema original da versão latina faz referência ao Salmo 37, 9: "Domine, ante te omne desiderum meum, et gemitus meus a te non est absconditus", ${ }^{27}$ mas, não fala em nenhum momento de flechas. Porém, na obra de Hugo, a relação entre imagem e referência Bíblica faz todo sentido, já que se trata na espiritualidade católica de um salmo penitencial o que corresponde à primeira seção do livro. Por causa disso, provavelmente, não foi mantida na versão inglesa. Mather substitui "gemidos" por "orações", mas, acrescenta o motivo da flecha: "we shoot the arrows of our desires away to heaven" ou "happy is the man that hath his quiver filled with these arrows." Sem dúvida nenhuma, se aproxima a linguagem religiosa usada pelo puritano Mather à linguagem textual e visual usada pelo católico Hugo. Aplicando a distinção de Chaoluan Kao (2018, p. 77-92) entre piedades "da glória celestial”, "terrestre”, “da koinonia" e "da disciplina diária”, Hugo promove os tipos um e quatro, Mather os tipos um e três e Spener o tipo três. Importante considerar que o aspecto comunitário da proposta das collegia pietatis de Spener já se encontrava de forma embrionária em livros de oração ingleses: Com outras palavras, Cotton Mather tinha assim como escolher entre diversas opções. ${ }^{28}$

A relação de Spener com a mística medieval passa pela sua edição e da Theologia Germanica considerada na época uma obra de Johann Tauler, seguindo aqui Lutero, e da Imitatio Christi de Tomas a Kempis ${ }^{29}$. Entretanto, o próprio Lutero tinha rejeitado uma mística neoplatônica que, por sua vez, seria mais a base da espiritualidade de Herman Hugo. Spener sabia disso, e o número significativo de livros de oração e guias devocionais protestantes ingleses que surgiu no século 16 substituía o que a obra de Herman Hugo procurava retomar. De fato, Richard F. Lovelace (1979, p. 36) destaca exatamente este aspecto de continuidade e rompimento quando ele afirma que

\footnotetext{
${ }^{26}$ Talvez haja ainda mais convergências. Josephine K. Piercy $(1967$, p. vi) menciona que o diário de Mather parece ser "[...] uma longa conversa com Deus". Isso seria, basicamente, a estrutura da narrativa da obra de Hugo.

${ }^{27}$ Salmo 38.9: "Senhor, diante de ti está todo o meu desejo, e o meu gemido não te é oculto."

28 Lovelace (1979, p. 38) afirma que "Depois do aparecimento simultâneo do pré-pietismo alemão (Johann Arndt) e do puritanismo ao final do século 17, houve um número considerável de empréstimos, polinização cruzada e simbioses entre formas inglesas-holandesas e alemãs de puritanismo/pietismo".

${ }^{29}$ Segundo Robert L. Wilken (1996, p. 82) Spener publicou em 1597 a versão da Theologia Germanica de Lutero junto com uma edição da Imitatio Christi de Kempis. WILKEN, Robert L. "Lutheran pietismo and catholic piety.". In: BRAATEN, Carl E; JENSON, Robert W. (eds.). The catholicity of the Reformation. Grand Rapids, Michigam e Cambrigde, Inglaterra: Eerdmans, 1996. p.

Rev. Pistis Prax., Teol. Pastor., Curitiba, v. 12, n. 3, p. xxx-xxx, set./dez. 2020
} 
[...] ambos provavelmente têm as suas raízes no misticismo popular do evangelho da mesma espécie como a Devotio Moderna que penetrava a reforma ortodoxa na Alemanha e na Renânia. Ambos eram esforços de construir uma nova piedade protestante, um estilo de vida cristã prático em bases teológicas luteranas ou reformadas, adaptando ou substituindo a piedade do misticismo e do ascetismo da contrarreforma.

Os verbos "adaptar" e "substituir" sinalizam a complexidade dos processos. Spener marca ainda mais fortemente as fronteiras entre reformas protestante e católica, inclusive, em sua apropriação e reorientação do termo Pia desideria, reintroduzindo o aspecto racional da metáfora. Já os Pia desideria do puritano Mather representam "[...] a expressão última da ênfase de Mather no desejo" (MIDDLEKAUFF, 1999, p. 406 [rodapé 38]) algo que por sua vez tem uma interface maior com o acento de Hugo. Apesar de Spener e Mather serem ambos considerados homens da piedade e da ciência ou de uma piedade vital capaz de unir as diversas formas do protestantismo na época, a linguagem dessa piedade vital de Mather é bem mais carregada de emoções do que a linguagem usada por Spener ${ }^{30}$. Assim representam os três, em termos interconfessionais, no caso de Hugo e Spener acentos previsíveis e, justamente no caso do puritano Mather, proximidades - ou transgressões? - surpreendentes. Os três religiosos, além de se articularem dentro dos seus ambientes confessionais - como o rigor maior de Hugo e Spener - fazem seus diferentes investimentos ou em uma linguagem religiosa mais racional ou mais afetiva no início até os meados da modernidade. Hugo representa a tensão entre a modernidade e reforma católica e investe no afeto; Spener integra na linguagem barroca uma linguagem racional e argumentativa; Mather parece partir para uma vivência em mundos separados nos quais o afeto move a religião e a razão a ciência.

\footnotetext{
30 Os dois grandes compositores protestantes do barroco viviam somente um pouco mais tarde e representam esta apropriação de elementos originários católicos à piedade e cultura protestante no campo da música: Johann Sebastian Bach (1685-1750) e Georg Friedrich Händel (1685-1759).

Rev. Pistis Prax., Teol. Pastor., Curitiba, v. 12, n. 3, p. 754-773, set./dez. 2020
} 


\section{A articulação dos aspectos racionais e afetivos das linguagens religiosas diante dos desafios da cultura da modernidade tardia: pia desideria}

$\mathrm{Na}$ atualidade, as fronteiras entre razão e afeto, cultura e confessionalidade, foram significativamente deslocadas. No início da modernidade, a razão precisava encontrar seu lugar, procura-se ao mesmo tempo entender e superar os feitos de um cartesianismo racionalista desencarnado "moderno", e como enfrentar um emocionalismo irracionalista "medieval", até "supersticioso" ou "mágico". ${ }^{11}$ Por um tempo, dominou, inclusive, no campo da religião um debate ainda tipicamente modernista entre a previsão do fim da religião pela secularização versus o medo da vingança da religião enterrando abaixo de si a vida moderna e as religiões modernas (Cf. BITTENCOURT FILHO, 2003). Já Carlos Eduardo Sell e Franz Josef Brüseke propuseram o modelo de uma "modernidade religiosa" que

proporciona uma mudança de paradigma que [...] permite ver as relações entre religião e modernidade de um novo ângulo, não mais destacando o declínio da religião na realidade secular (secularização) e nem sugerindo o declínio da realidade secular diante de uma suposta revanche das religiões (retorno do sagrado)" (SELL; BRÜSEKE, 2006, p. 187).

Isso fica ainda mais claro quando não se reduz a modernidade ao seu aspecto racional e a religião a seu aspecto emotivo e se percebe que estamos em uma nova fase de avaliação dessa. Foram introduzidos nesse debate conceitos novos como, por exemplo, a "inteligência social" de Robert L. Thorndike e a "inteligência emocional" de Daniel Goleman. Para a discussão sobre o respetivo impacto da modernidade na atualidade, Edgar Morin (2013) destacou os "erros da razão", a "falsa racionalidade" como sua "disjunção e especialização fechada". Dentro da sua discussão sobre a condição humana, acresceu, seguindo "a concepção do cérebro triúnico", à bias "razão - afeto" o elemento da "pulsão" e descreveu a relação entre os três como "[...] não apenas complementares, mas antagônicas, comportando conflitos bem conhecidos

\footnotetext{
${ }^{31}$ O que explicaria, em parte, por um lado, a forte pressão sobre o protestantismo histórico, a teologia acadêmica e movimentos como, por exemplo, a teologia da libertação e por outro lado, a ascensão de igrejas neopentecostais e parcialmente, do pentecostalismo e dos movimentos carismáticos dentro das confissões estabelecidas.
}

Rev. Pistis Prax., Teol. Pastor., Curitiba, v. 12, n. 3, p. xxx-Xxx, set./dez. 2020 
entre a pulsão, o coração e a razão", não obedecendo "à hierarquia razão $\leftrightarrow$ afetividade $\Theta$ pulsão", mas, seguindo uma "relação instável, mutante, rotativa" na qual "a racionalidade não dispõe [...] de poder supremo" e que ela por sua vez pode ser "dominada, submersa ou mesmo escravizada pela afetividade ou pela pulsão" (MORIN, 2013, p. 171). Por um lado, Morin de certo modo, explica e ao mesmo tempo desafia leituras clássicas particularistas confessionais dos pia desideria e as transgressões entre eles. Trata-se de reações antagônicas, mas, também de reaproximações. Já mencionei o potencial da antiga metáfora dos pia desideria, pelo seu significado originário mais amplo e integrador dos aspectos tanto racionais como afetivos. Mas esse seu potencial não deve ser reduzido a uma simples prescrição das linguagens religiosas tradicionalmente formuladas, já que elas foram criadas para articular a dimensão religião no início da modernidade, ou seja, de 250 até 350 anos atrás. O cenário mudou, desde já, profundamente, e precisa-se lidar não somente com as ambiguidades da antiguidade e da época medieval, como era o caso no início da modernidade, mas agora inclusive com as ambiguidades da própria modernidade que não passam, por acaso, por uma nova reflexão sobre a relação dos papeis da razão e da afetividade, sob uma nova consideração daquilo que Morin descreve como pulsão. Hugo, Spener e Mather acentuaram seus Pia desideria para seus tempos em um ambiente interconfessional mais hostil e, diferente do que antes, não se espera mais que os discursos inovadores criados terão uma validade parecida. Mas o desafio de relacionar aspectos racionais da religião - que são também aqueles aspectos mais facilmente comunicáveis - com os aspectos afetivos da religião - que representam os aspectos vitalizantes e vivos, ou seja, mais atraentes, da religião — não se resolveu e provavelmente nunca se resolverá uma vez para sempre. Portanto, se Morin, Sell e Brüsecke captam bem o espírito da cultura contemporânea da modernidade tardia, a prescrição das leituras anteriores dos pia desideria cairá em um vácuo, estabelecendo, no máximo, mundo paralelos onde a ênfase no sobrenatural ignora, tendencialmente, as formas reais da corporeidade e da vulnerabilidade humana, e onde o caráter inacabado do ser humano e a ênfase na paixão no sentido de uma forte comoção se casa com uma opção pela irracionalidade e pelo extraordinário. Como Hugo, Spener e Mather iam responder, não se sabe; mas se sabe que a sua mera prescrição não 
resolverá. Em vez disso, estamos diante de uma época nova, por um lado, certamente com um entusiasmo mais moderado em relação à modernidade tardia e seu potencial do que era o caso no início da renascença; por outro lado, com uma nova valorização do aspecto afetivo da religião sob observação do seu potencial de dominar ou até escravizar indevidamente e da sua relação instável, mutante e rotativa. Que isso, consequentemente, fosse levar a um debate construído de uma forma mais interconfessional, eu presumo, mesmo que provavelmente sempre haverá retrocessos temporários que criam "definições" ou seja, fronteiras, onde se espera hoje aparecer pontes, inclusive, por pia desideria contextualizados, eventualmente, menos confessionais e mais interconfessionais, refazendo tipologias clássicas. Os três autores valorizaram essa mesma metáfora por serem promotores de movimentos religiosos, militantes religiosos em busca da vitalização da religião e dos sujeitos religiosos.

\section{Considerações finais}

Mesmo que os três projetos espirituais não intencionam na sua época a superação das distinções entre as reformas católica e protestante, eles estabeleceram entre eles um vínculo pelo uso da mesma metáfora, o que fica evidente, primeiro, no caso de Hugo e Mather, pela reaproximação das linguagens religiosas, segundo, comparando os três, por procurar lidar com a razão e o afeto e a dinâmica antagônica entre eles. O século 20 demonstrou de forma trágica como um terceiro elemento, chamado por Morin "pulsão", desafiou e desafia tanto as expressões racionais como as expressões afetivas da vida, inclusive da vida religiosa.

Isso desafia à ampliação da ideia dos pia desideria por um terceiro aspecto e por uma noção da religião mais dinâmica da interrelação entre razão, afetividade e pulsão, que não se atende com modelos religiosos predominantemente racionalistas ou emocionalistas. Além de iluminar o debate histórico em relação à sobrevivência de aspectos da piedade católica no pietismo alemão e mediante o aspecto pietista no puritanismo inglês, orientam-nos os pia desideria em seu significado originário mais amplo e integrador ao propor uma relação mais dinâmica entre a razão e o afeto, como aspectos essenciais tanto para a vida como para a religião na contemporaneidade, partindo da ampla experiência confessional com essa linguagem metafórica e, ao 
mesmo tempo, indo além dela. Afinal, interconfessionalidade e interculturalidade, não se encontram dadas, mas se constroem por linguagens.

\section{Referências}

AULER, I. C. F. Spiritu, Corde et Practice: A cultura visual nas meditações de Jerônimo Nadal. Rio de Janeiro: PUC Rio, 2007. Disponível em: http://www.pucrio.br/pibic/relatorio_resum02007/relatorios/HIS/his_isabel_cristina_fernandes_auler.pdf. Acesso em: 20 ago. 2019.

BERNHARDT, V. The American Pietism of Cotton Mather: Origins of American Evangelicalism. By Richard F. Lovelace. The Journal of American History, v. 67, n. 2, p. 388, 1980. DOI: https://doi.org/10.2307/1890428.

BITTENCOURT FILHO, J. Matriz religiosa brasileira: religiosidade e mudança social. Petrópolis: Vozes: Koinonia, 2003.

BRANDT, D. H. Phillip Jacob Spener: Pia desideria. Resumo contextual e programático do pia desideria, desejos piedosos. Disponível em: https://www.luteranos.com.br/public/download.php?nome=piadesideria-desejos-piedosos-resumo-contextual-e-programutico\&file $=201303 / 7404357 \mathrm{~b} 81 \mathrm{a} 3 \mathrm{~d} 861 \mathrm{f} 75532671 \mathrm{a} 6625 \mathrm{e} 7$. pdf. Acesso em: 1 maio 2020.

BROWN, C. L. Christianity and the campaign against slavery and the slave trade. In: BROWN, S. J.; TACKETT, T. (eds). The Cambridge History of Christianity, v. 3 [Enlightenment, Reawakening and Revolution 1660-1815]. New York: Cambridge University Press, 2008. p. 517-535.

BUSCHHOFF, A. Die Liebesemblematik des Otto van Veen: die Amorum Emblemata (1608) und die Amoris Divini Emblemata (1615). Bremen: H.M. Hauschild, 2004.

COLLINS, M.; PRICE, M. A. História do cristianismo: 2000 anos de fé. São Paulo: Loyola, 2000. 248p.

DAMRAU, P. The reception of English Puritan literature in Germany. London: MHRA, 2006. 216p.

DREHER, M. N. A Igreja Latino-Americana no contexto mundial. São Leopoldo: Editora Sinodal, 1999. 244p.

HUGO, H. Pia desideria emblematis, elegiis \& affectibus. Patrum illustrata. Antverpiae: Vulgauit Boëtius a Bolswert, Typis Henrici Aertssenii, 1624.

HUGONIS, H. Piorum Desideriorum. Libri três. Weimar: Klassik Stiftung Weimar, Herzogin Anna Amalia Bibliothek, 2018.

$\mathrm{KAO}, \mathrm{C}$. Reformation of prayerbooks: the humanist transformation of early modern piety in Germany and England. Göttingen: Vandenhoeck \& Rupprecht, 2018. 
KENNEDY, R. The first American evangelical: a short life of Cotton Mather. Grand Rapids, MI: Wm. B. Eerdmans Publishing Co., 2015. (Coletânea: Library of Religious Biography (LRB)).

LOVELACE, R. F. The American Pietism of Cotton Mather: Origins of American evangelicalism. Michigan: Grand Rapids, 1979. 350p.

MAGALHÃES FILHO, G. B. Teologia, Espiritualidade e Protestantismo. São Paulo: Editor Vida, 2014. 125p.

MATHER, C. Magnalia Christi Americana: or the ecclesiastical history of New England from its first planting in 1620, until the year of Our Lord 1698. London: Thomas Parhurst, 1702. 821p.

MATHER, C. Pia Desideria: or, the smoaking flax, raised into a sacred flame: in a short and plain essay upon those pious desires, which are the introduction and inchoation of all vital piety, delivered unto a religious society of young people; on the Lord's-Day-evening, Boston: Printed by S. Kneeland for S. Gerrish, at his shop in Cornhill, 1722.

MATHER, C. Pia Desideria: or, the smoaking flax, raised into a sacred flame: in a short and plain essay upon those pious desires, which are the introduction and inchoation of all vital piety, delivered unto a religious society of young people; on the Lord's-Day-evening, 1722. Farmington Hills, MICH.: Thomson Gale, 2005.

MEID, V. Die deutsche Literatur im Zeitalter des Barock: Vom Späthumanismus zur Frühaufklärung 1570-1740. 2. ed. Muenchen: Beck, 2009. (Coletânea: Geschichte der deutschen Literatur: Von den Anfängen bis zur Gegenwart, vol. 5).

MIDDLEKAUFF, R. The Mathers: three generations of Puritan intellectuals, 1596-1728. Berkeley, Los Angeles, London: University of California Press, 1999.

MORIN, E. Os setes saberes necessários à educação do futuro. São Paulo: Editora Cortez e Unesco, 2013.

NOLL, M. A. “British and French North America to 1765". In: BROWN, S. J.; TACKETT, T. (eds). The Cambridge History of Christianity, v. 3: Enlightenment, Reawakening and Revolution 16601815. New York: Cambridge University Press, 2008. p. 392-410.

PAIS, A. "Inquietações da alma: reflexões sobre o simbolismo presente nos temas coadjuvantes de núcleos azulejares portugueses". Revista de História de Arte, Lisboa, Portugal, v. 3, p. 183-199, 2007.

PIERCY, J. K. "Introduction". In: MATHER, C. Bonifacius: an essay ... to do good (1710). A facsimile reproduction with an introduction by Josephine K. Piercy. Gainesville, Florida: Scholars' Facsimiles\& Reprints, 1967. p. v-xxii.

RASPA, A. Arwaker, Hugo's Pia Desideria and Protestant poetics. In: Renaissance and Reformation / Renaissance et Réforme, Toronto, ano 24, v. 2, p. 63-75, 2000.

REISNER, P. Cotton Mather als Aufklärer: Glaube und Gesellschaft im Neuengland Neuengland der Frühen Neuzeit. Berlin: Vandenhoeck \& Ruprecht, 2012. 350p. 
RENDERS, H. "Os livros com emblemas de coração de A. Wierix e B. van Haeften: O caminho tríplice da mística apofática sem e com a ênfase na mística catofática da Imitatio Christi”. Revista Didaskalia, Lisboa, v. 47, n. 1, p. 239-262, 2017.

SATTLER, G. R. “Philipp Jacob Spener, Pia Desideria (1675)”. In: MAGILL, F. N.; McGREAL, I. P. (eds.). Christian spirituality: the essential guide to the most influential spiritual writings of the Christian tradition. San Francisco: Harper \& Row, 1988. p. 320-325.

SELL, C. E. BRÜSECKE, F. J. Mística e sociedade. Itajaí: Universidade do Vale de Itajaí; São Paulo: Paulinas, 2006.

SIVERMN, K. The life and times of Cotton Mather. New York: Harper \& Row, 1984.

SPENER, P. J. Pia Desideria, ou sinceros desejos de uma reforma da verdadeira Igreja Evangélica de acordo com a vontade de Deus juntamente com algumas propostas cristãs simples para a sua implementação. Edição de David Zunner impresso por Johann Diederich Fritgen, 1676.

SPENER, P. J. Pia desideria. $2^{\mathrm{a}}$ ed. Köhler. Franckfurt am Mayn: Verlegung Johann David Zunners: Druckts Johann Dieterich Friedgen, 1676.

SPENER, P. J. Pia desideria. Trad. Theodore Tappart. Philadelphia, 1664.

SPENER, P. J. Historia insignium illustrium seu Operis heraldici pars specialis. 1680.

SPENER, P. J. Mudança para o Futuro; Pia Desideria. Curitiba: Encontrão; São Bernardo do Campo: Ciências da Religião, [s. ano].

SPENER, P. J. Pia desideria. $2^{\text {a }}$ ed. Editor: Kurt Aland. Berlin: Walter de Gruyter, 1955.

SPENER, P. J. Pia desideria. Giessen / Basel: Brunnen, 2005.

SPENER, P. J. Theatrum nobilitatis Europeae, tabulis progonologicis praecipuorum in cultiori christiano orbe magnatum et illustrium progenitores. 1671.

VERRI, G. M. W. Tinta sobre papel: livros e leituras em Pernambuco no século XVIII. v. 2. RECIFE, PE: Editora Universitária UFPE, 2006.

WARD, W. R. Evangelical awakenings in the North Atlantic world". In: BROWN, S. J.; TACKETT, T. (eds). The Cambridge History of Christianity. v. 3. [Enlightenment, Reawakening and Revolution 1660-1815]. New York: Cambridge University Press, 2008. p. 329-347.

WARNKE, C.-P. Symbol, Emblem, Allegorie: die zweite Sprache der Bilder. Köln: Deubner Verlag für Kunst, Theorie und Praxis, 2005.

RECEBIDO: $28 / 08 / 2020$

APROVADO: 08/12/2020
RECEIVED: 08/28/2020

APPROVED: $12 / 08 / 2020$
RECIBIDO: $28 / 08 / 2020$

APROBADO: 08/12/2020 